\title{
A DELIMITAÇÃO DA CIÊNCIA JURÍDICA E A DEFINIÇÃO DE NORMA JURÍDICA NA TEORIA PURA DO DIREITO
}

\author{
Rodrigo Borges Valadão ${ }^{1}$
}

\begin{abstract}
En forma desprovida de todo espíritu crítico, ha mezclado la jurisprudencia con la psicología y la biología, con la ética y la teología. Hoy en día no hay ciencia especial en cuyo recinto el jurisperito se considere incompetente para penetrar. Desde luego, él cree puder realzar su prestígio científico precisamente tomando en préstamo de otras disciplinas, con la que está perdida, naturalmente, la verdadeira ciencia jurídica. ${ }^{2}$
\end{abstract}

Hans Kelsen

\section{Resumo}

Ao (i) estabelecer o status das ciências culturais, em contraposição às ciências naturais, e ao (ii) distinguir o Direito de outros fenômenos sociais, Hans Kelsen delimitou a norma jurídica como objeto da Ciência do Direito. A partir daí buscou apresentar um conceito de norma jurídica, conceito este que sofreu sucessivas alterações durante cerca de meio século.

Palavras-chave: Hans Kelsen; Ciência do Direito; Delimitação do seu Objeto; Norma Jurídica; Definição

\section{INTRODUÇÃO}

A Teoria Pura do Direito - empreitada teórica iniciada pelo austríaco Hans Kelsen em $1911^{3}$ e a qual ele iria dedicar toda a sua vida - é normalmente apontada por iniciar uma versão normativista do Positivismo Jurídico.

Que a norma jurídica desempenha um papel fundamental na construção e no desenvolvimento da Teoria Pura do Direito é por demais óbvio. Menos óbvio, no entanto, é o trajeto epistemológico percorrido por Kelsen para a delimitação da norma jurídica como objeto da Ciência do Direito.

O presente trabalho se propõe, num primeiro momento, a demonstrar o caminho percorrido por Kelsen para a delimitação da norma jurídica como o objeto da sua Ciência Jurídica. Num segundo momento, será demonstrado, de forma panorâmica, a evolução conceitual da norma jurídica na Teoria Pura do Direito. Ao final,

\footnotetext{
${ }^{1}$ Doutorando em Teoria do Direito pela Albert-Ludwigs-Universität Freiburg, Alemanha. E-mail: rod_valadao@yahoo.com.br ${ }^{2}$ KELSEN, Hans [1933]. La Teoría Pura del Derecho. Trad. Jorge G. Tijerina. 2a ed., Buenos Aires: Posada, 1941, p. $25-26$.

${ }^{3}$ As bases fundamentais da Teoria Pura do Direito foram lançadas por Kelsen em seu trabalho de Habilitação, denominado Hauptprobleme der Staatsrechtslehre, entwickelten aus der Lehre vom Rechtssatze. Tübingen: JCB Mohr, 1911.
} 
será apresentada uma definição de norma jurídica compatível com as sucessivas alterações conceituais sofridas em meio século de contínuo desenvolvimento.

\section{HANS KELSEN: UM HOMEM DA SUA ÉPOCA}

Embora nascido em Praga, Hans Kelsen teve sua educação e formação acadêmica em Viena, na Áustria. ${ }^{4}$ Mudou-se para lá com sua família em 1884, aos 3 (três) anos de idade e por lá permaneceu, salvo por pequenos períodos, até 1930, aos 49 (quarenta e nove) anos. ${ }^{5}$

Exatamente neste período desenvolvia-se ali uma sociedade peculiar, culturalmente brilhante, havendo quem a considere como "a Atenas do século XX" ${ }^{6}$ Num ambiente permeado por música e arte, brotavam correntes filosóficas e científicas que alimentaram a cultura ocidental por todo o século. ${ }^{7}$ Em linhas gerais, esta cultura era baseada na luta pela objetividade, pelo empirismo e pela depuração dos conceitos, em síntese, pela desmistificação da vida e do pensamento. ${ }^{8}$

Pode-se dizer que Kelsen foi um legítimo produto de sua época. Num dos primeiros parágrafos de sua Teoria Pura do Direito, de 1934, ao expor a "pureza" de seu projeto teórico, ${ }^{9}$ encontra-se expressa a tensão histórica, sociológica e epistemológica da Europa no início do século XX, com especial ênfase na Teoria do Direito. Segundo Kelsen,

"una mirada sobre la ciencia jurídica tradicional, tal como se ha desenvuelto en el curso de los siglos XIX y XX, mostra claramente cuán distante se halla de corresponder a la exigencia de la pureza. En forma desprovida de todo espíritu crítico, ha mezclado la jurisprudencia con la psicología y la biología, con la ética y la teología. Hoy en día no hay ciencia especial en cuyo recinto el jurisperito se considere incompetente para penetrar. Desde luego, él cree puder realzar su prestígio científico precisamente tomando en préstamo de otras disciplinas, con la que está perdida, naturalmente, la verdadeira ciencia jurídica." 10

Com base neste horizonte crítico, Kelsen iria dedicar toda sua vida ao projeto de desenvolver uma teoria jurídica pura, isto é, purificada de toda a ideologia política e de todos os elementos da ciência natural. ${ }^{11}$ Seu objetivo era elevar a teoria jurídica

\footnotetext{
${ }^{4}$ Na verdade, Viena era a capital do Império Austro-Húngaro, uma Monarquia Parlamentarista de cunho político eminentemente liberal, entre os anos de 1867 e 1918.

${ }^{5}$ Para maiores detalhes. Cf. MÉTALL, Rudolf Aladár [1976]. Hans Kelsen - Vida y Obra. Trad. Javier Esquivel. Mexico DF: Instituto de Investigaciones Jurídicas - UNAM, 1976, p. 10 a 64.

${ }^{6}$ SCHMILL, Ulises [1976]. Prólogo. In: MÉTALL, Rudolf Aladár [1976]. Hans Kelsen - Vida y Obra. Trad. Javier Esquivel. Mexico DF: Instituto de Investigaciones Jurídicas - UNAM, 1976, p. 1.

${ }^{7}$ Idem, p. 2.

${ }^{8}$ Ibidem, p. 4.

9 'Si ella se califica como teoría 'pura' del derecho, es porque pretende garantizar uno conocimiento dirigido solamente hacia el derecho, y porque pretende eliminar de este conocimiento todo lo que no pertenece al objeto exactamente seňalado como derecho. Es decir: quiere liberar a la ciencia jurídica de todos los elementos estrańos." KELSEN, Hans [1933]. La Teoría Pura del Derecho. Trad. Jorge G. Tijerina. 2a ed., Buenos Aires: Posada, 1941, p. 25.

${ }^{10}$ Idem, p. 25-26.

${ }^{11}$ KELSEN, Hans [1960]. Teoria Pura do Direito. Trad. João Baptista Machado. 6a ed., São Paulo: Martins Fontes, 1998, p. XI.
} 
"à altura de uma genuína ciência, de uma ciência do espírito (...) explica[ndo] não as suas tendências endereçadas à formação do Direito, mas as suas tendências exclusivamente dirigidas ao conhecimento do Direito, e aproximar o tanto quanto possível os seus resultados do ideal de toda a ciência: objetividade e exatidão" ${ }^{12}$

Para alcançar este objetivo, deparou-se com um duplo desafio. Em primeiro lugar, teve que lançar as bases epistemológicas e metodológicas de sua ciência jurídica. E, aqui, o desafio consistia, basicamente, em (i) estabelecer o status das ciências culturais, em contraposição às ciências naturais, bem como seus princípios de regência e (ii) definir, neste quadrante, o lugar ocupado pelo Direito, distinguindo-o de outros fenômenos sociais. Em segundo lugar, uma vez que, segundo Kelsen, a teoria jurídica deveria ser consciente de sua especificidade, ${ }^{13}$ foi preciso delimitar o objeto de sua ciência jurídica. É justamente este percurso que voltamos a percorrer.

\section{O DIREITO COMO TÉCNICA SOCIAL ESPECÍFICA}

A história do pensamento humano sempre foi marcada por diversas formas de dualismo. Céu e inferno, noite e dia, calor e frio, enfim, diversos dualismos apresentam-se como categorias fundamentais da construção do nosso conhecimento. Todavia, o reconhecimento de alguns destes dualismos não foi sempre algo de per si evidente. E o reconhecimento de um deles, essencial para o pensamento científico, seguiu, durante milênios, a mesma sorte: o dualismo existente entre natureza e sociedade.

De fato, o homem primitivo sempre entendeu que a natureza era regulada pelas mesmas leis que regulavam a sociedade. A idéia de retribuição era aplicada indistintamente aos fatos naturais e aos fatos sociais, pois a natureza era vista como parte intrínseca de sua sociedade. ${ }^{14}$

Quando a natureza é interpretada conforme o princípio da retribuição, os seus fenômenos, na medida em que requerem explicação, são relacionados com os indivíduos ou com o grupo a que pertencem. Em alguns casos, o próprio grupo podia ser coletivamente responsável pela conduta de um ou mais indivíduos. ${ }^{15}$ Assim, um desastre natural, por exemplo, era explicado da mesma forma que a reação social imputada a um ilícito: uma punição divina dirigida contra aquele que praticou uma conduta socialmente indesejada.

Somente a partir do século XVIII é que a natureza passou a ser explicada em termos distintos. Em contraposição aos fatos sociais, a explicação dos fenômenos naturais enquanto efeitos passam a ser relacionados a outros fatos naturais enquanto causas. Neste passo, estes fenômenos deixam de ser mero reflexo da conduta dos indivíduos contrária ou conforme às normas sociais. ${ }^{16}$ A conduta humana deixa de ser a base da explicação do mundo natural e a idéia de retribuição perde seu sentido.

\footnotetext{
${ }^{12}$ Idem, p. XI.

${ }^{13}$ Ibidem, p. XI.

${ }^{14}$ KELSEN, Hans [1946]. Society and Nature: a Sociological Inquiry. New Jersey: The Lawbook Exchange, 2000, p. vii.

${ }^{15}$ Idem, p. 263 e 264.

${ }^{16}$ Ibidem, p. 263 e 264.
} 
Assim, embora formem uma única realidade fática, verificou-se que natureza e sociedade correspondem a diferentes sistemas e, por isso, são objetos que demandam a construção de um instrumental teórico específico. De um lado, o mundo naturalé entendido como o plano existencial (mundo físico) determinado pela ocorrência de um nexo necessário (princípio da causalidade), o qual o pensamento humano meramente constata. De outro lado, o mundo cultural, de caráter normativo, explicável pelo princípio da imputação (relação de condição e conseqüência atribuída pelo homem), quando há descrição de uma relação específica estabelecida entre dois fatos diferenciados dos acontecimentos causais, em virtude de ser essa relação alheia aos fatos que descreve. ${ }^{17}$

Conectados através do princípio da causalidade, os elementos fáticos formam o sistema natural (natureza); conectados por um princípio diverso, o princípio da imputação, estes mesmos elementos formam um sistema cultural (sociedade). ${ }^{18}$ Assim, ao contrário da causalidade natural, a "causalidade cultural" (leia-se: a imputação) encontra sua razão de ser apenas nas normas que transformam as ações humanas, enquanto fatos naturais, em ações humanas normativamente qualificadas, ${ }^{19}$ ou seja, dotadas de um sentido autônomo, socialmente reconhecido. O que qualifica o fato natural como um fato social não é a sua facticidade, não é o seu ser natural, isto é, o seu ser tal como determinado pelo princípio da causalidade e encerrado no sistema da natureza, mas o sentido objetivo objetivo que está ligado a este ato, a significação que ele possui. ${ }^{20}$

Desta forma, a simples convivência entre os indivíduos assume uma dupla dimensão: em si um fenômeno natural, esta convivência torna-se um fenômeno social pelo simples fato de ser regulamentada. A sociedade é a convivência ordenada ou, mais exatamente, a sociedade é o próprio ordenamento da convivência dos indivíduos. ${ }^{21}$

Portanto, a sociedade nada mais é do que um complexo de regras que determinam como o indivíduo deve conduzir-se em relação a outros indivíduos. Se a função de toda ordem social é ocasionar certa conduta recíproca dos indivíduos, ou seja, induzi-los a certa conduta positiva (ação) ou negativa (omissão), é justamente através destas regras que o grupo social confere um determinado sentido ${ }^{22}$ a determinas condutas desejadas ou indesejadas. Tais regras são chamadas normas. ${ }^{23}$

Estas normas, entretanto, não pertencem a um único sistema. Na verdade, a sociedade é composta por

\footnotetext{
${ }^{17}$ SGARBI, Adrian [2007]. Hans Kelsen - Ensaios Introdutórios (2001-2005). Rio de Janeiro: Lumen Iuris, 2007, p. 7.

${ }^{18}$ KELSEN, Hans [1946]. Society and Nature: a Sociological Inquiry. New Jersey: The Lawbook Exchange, 2000, p. vii.

${ }^{19}$ KELSEN. Hans [1945]. Teoria Geral do Direito e do Estado. Trad. Luís Carlos Borges. 3a ed., São Paulo: Martins Fontes, 1998, p. 64.

${ }^{20}$ KELSEN, Hans [1960]. Teoria Pura do Direito. Trad. João Baptista Machado. 6a ed., São Paulo: Martins Fontes, 1998, p. 4.

${ }^{21}$ KELSEN, Hans [1941]. O Direito como Técnica Social Específica. In: KELSEN, Hans [1957]. O que é Justiça?. Trad. Luis Carlos Borges. São Paulo: Martins Fontes, 1998, p. 225.

${ }^{22}$ Note-se, aqui, que a noção de norma como sentido objetivo de um ato de vontade somente seria desenvolvida na fase cética do pensamento kelseniano.

${ }^{23}$ Idem, p. 225.
} 
diversas ordens distintas, que, em sua totalidade, formam a ordem social. Cada ordem parcial ${ }^{24}$ distingue-se das demais em 2 (dois) pontos específicos: i) pela forma que cada uma busca realizar a conduta socialmente desejada; ii) pelo grau de organização da sanção institucionalizada por cada uma destas ordens.

De fato, num primeiro momento, uma ordem normativa pode indicar ao indivíduo que a conduta conforme suas prescrições será retribuida com certas vantagens e que a conduta contrária às mesmas prescrições será retribuída com certas desvantagens. Esta promessa de retribuição funciona como um motivo para a conduta, pois o indivíduou pode nutrir um desejo pela vantagem que se promete ou um temor da desvantagem com que se ameaça. ${ }^{25}$

Por sua vez, estas motivações para a realização de determinada conduta podem ser diretas ou indiretas. São diretas quando a simples prática do ato ou da omissão aparece como retribuição suficiente ao indivídio. Nestes casos, quaisquer outras promessas ou ameaças são desnecessárias, pois a mera idéia de uma norma que decreta esta conduta é suficiente para a conduta em conformidade com a norma. Este seria o caso, por exemplo, dos sistemas morais altamente desenvolvidos. ${ }^{26}$

Todavia, na realidade social, a motivação direta, isto é, a prática pelo indivíduo da ação socialmente desejada diante da simples existência da norma, raramente é encontrada de forma pura. ${ }^{27}$ Em alguma medida, toda obediência à norma está associada à aprovação dos semelhantes e a desobediência à desaprovação. ${ }^{28}$ Esta reação do grupo à conduta do indivíduo, desejada ou repudiada, denomina-se sanção.

Assim é que, num segundo momento, a sanção estipulada pela ordem assume uma importância decisiva para sua caracterização. Isto porque, sob o ponto de vista realista, a diferença decisiva entre as diversas ordens não repousa na presença ou ausência de sanções. Todo e qualquer ordenamento social recorre à técnica de motivação indireta para se fazer eficaz, ${ }^{29}$ sendo, em certa medida, 'sancionado' pela reação específica da comunidade à

\footnotetext{
${ }^{24}$ Impõe-se, aqui, esclarecer o seguinte: no que diz respeito à configuração das ordens normativas que compõem a sociedade, Kelsen nunca utilizou o termo "ordem parcial", valendo-se do termo ordem ("order") para referir-se tanto às ordens normativas parciais (direito, moral, regilião) e quanto à ordem normativa total (sociedade). Cf. KELSEN, Hans [1941]. The Law as Specific Technique. In: KELSEN, Hans [1957]. What is Justice? - Justice, Law and Politics in the Mirror of Science. New Jersey: The Lawbook Exchange, 2000, p. 231.

${ }^{25}$ KELSEN, Hans [1941]. O Direito como Técnica Social Específica. In: KELSEN, Hans [1957]. O que é Justiça?. Trad. Luis Carlos Borges. São Paulo: Martins Fontes, 1998, p. 225.

${ }^{26}$ Idem, p. 226.

${ }^{27}$ Nota-se, aqui, uma leve contradição no discurso kelseniano. Num primeiro momento, Kelsen sustenta, ao menos de maneira implícita, que: "conforme a maneira como a conduta socialmente desejada é ocasionada, podem-se distinguir vários tipos de ordens". Logo após, Kelsen afirma que "na realidade social (a) motivação direta raramente é encontrad(a) de forma pura. (...) A única diferença é que certas ordens sociais proveêm sançôes definidas, ao passo que, em outras, as sançôes consistem na reação automática da sociedade, não expressamente provida pela ordem." Ibidem, p. 225 e 226.

${ }^{28}$ Ibidem, p. 226.

${ }^{29}$ Neste particular, nota-se uma imprecisão no discurso kelseniano. Em sua obra inalgural, Kelsen refere-se às normas jurídicas como normas heterônomas e às normas morais como normas autônomas (sem fazer distinção entre a moral individual a moral positiva), chegando a dizer que "tratándose de normas morais, [perdese] de vista la diferencia formal entre el ser y el deber ser". Mais tarde, Kelsen reconhece que todos os sistemas normativos são, em certa medida, heterônomos, porque garantidos através de
} 
conduta de seus membros que corresponde à norma ou que diverge dela.

Deste modo, em que pese a natureza da motivação a que recorrem as diversas ordens, a principal diferença entre as ordens normativas é a organização e a natureza das respectivas sanções. Em primeiro lugar, enquanto no Direito a sanção aparece na forma de uma coerção socialmente organizada, a reação contra a conduta equívoca prevista por outros sistemas normativos, principalmente a moral, ${ }^{30}$ não é provida pela ordem normativa nem é, se provida, socialmente organizada. ${ }^{31}$

Em segundo lugar, o Direito viabiliza sua sanção através da ameaça de coerção, isto é, da ameaça do uso da força física contra o indívíduo que praticar a conduta contrária àquela prescrita pelo Direito. ${ }^{32}$ Em síntese: o Direito é uma ordem social parcial que, através da ameaça de coerção (motivação indireta), isto é, da ameaça de uso da força física monopolizada por uma instituição (Estado), garante a conduta socialmente desejada dos seus indivíduos. ${ }^{33}$

Por todo o exposto, conclui Kelsen que:

há um elemento comum que justifica essa terminologia, que permite à palavra 'Direito' surgir como a expressão de um conceito com um significado social muito importante. Pois a palavra refere-se à técnica social específica de uma ordem coercitiva, que, apesar das enormes diferenças entre o Direito da antiga Babilônia e o dos Estados Unidos de hoje, entre o Direito dos ashantis da África Ocidental e o Direito da Suíça, na Europa, é essencialmente a mesma para todos esses povos que diferem tão amplamente em tempo, lugar e cultura - a técnica social que consiste em ocasionar a conduta social desejada dos homens por meio de ameaça de coerção no caso da conduta contrária. ${ }^{34}$

Logo, em que pese a extraordinária diferença no espaço e no tempo entre todas as ordens sociais registradas pela história, há em todas elas um elemento comum. É justamente este elemento que permite uma caracterização teórica do Direito, permitindo que todas as ordens jurídicas sejam descritas a partir de categorias gerais. E a análise destas categorias gerais deve ser feita de sorte a garantir uma pureza metodológica que exclua

sanções. Ao que parece, não há propriamente uma alteração ou contradição no pensamento de Kelsen, e sim uma imprecisão conceitual, por não ter sido feito, neste ponto, uma necessária distinção entre a moral individual (esta sim autônoma) e a moral positiva (esta, em certa medida "garantida" através de sanções), uma vez que esta distinção pode ser encontrada em outros escritos, como, por exemplo, no seu livro "Teoria Gera do Direito e do Estado", de 1945, ou, ainda, no livro "Teoria Geral das Normas", de 1979. Cf, respectivamente, KELSEN, Hans [1911]. Problemas Capitales de la Teoría Jurídica del Estado. Trad. Wenceslao Roces. 2a ed., Mexico DF: Editorial Porua, 1987, p. 30-40; KELSEN, Hans [1941]. O Direito como Técnica Social Específica. In: KELSEN, Hans [1957]. O que é Justiça?. Trad. Luis Carlos Borges. São Paulo: Martins Fontes, 1998, p. 230; KELSEN, Hans [1945]. Teoria Geral do Direito e do Estado. Trad. Luís Carlos Borges, 3a ed., São Paulo: Martins Fontes, 1998, p. 12 et KELSEN, Hans [1979]. General Theory of Norms. Oxford: Clarendon Press, 1991, p. 4.

${ }^{30}$ Noutros sistemas normativos, como a maioria dos sistemas normativos religiosos, esta reação é fortemente institucionalizada, não havendo, neste particular, grande distinção entre estas técnicas de controle social. Todavia, quanto a natureza da sanção, os sistemas normativos religiosos são de caráter transcendental, não havendo o uso da ameaça da força física para tutelar sua efetividade.

${ }^{31}$ KELSEN, Hans [1941]. O Direito como Técnica Social Específica. In: KELSEN, Hans [1957]. O que é Justiça?. Trad. Luis Carlos Borges. São Paulo: Martins Fontes, 1998, p. 230.

${ }^{32}$ Idem, p. 231.

${ }^{33}$ KELSEN, Hans [1944]. Peace Through Law. 3ª ed., New Jersey: The Lawbook Exchange, 2000, p. 3. 
todos os elementos estranhos à sua descrição.

\section{ENTRE FATOS E NORMAS: O CAMINHO PERCORRIDO PELA TEORIA PURA DO DIREITO PARA A DELIMITAÇÃO DO SEU OBJETO}

Como visto, Kelsen sempre reconheceu a realidade complexa assumida por esta técnica social, denominada Direito. Isto explicaria, até certo ponto, a confusão entre a ciência do Direito e outras ciências, como a psicologia e a sociologia, como a ética e a teoria política, pois estas ciências se referem a objetos que indubitavelmente têm uma estreita conexão com o Direito. ${ }^{35}$ Não obstante, uma teoria jurídica consciente de sua especificidade deve partir do pressuposto que o Direito possui, nesta complexidade, uma realidade própria e um objeto bem definido: a legalidade autônoma de uma esfera de sentido. ${ }^{36}$ De certo modo, é possível dizer que o Direito está conectado com a realidade social sem, no entanto, pertencera ela. ${ }^{37}$

Entretanto, por dezenas de séculos, a teoria jurídica seguiu caminhos seguros e bem definidos, ignorando por completo a especificidade do seu objeto e imiscuindo-se nos domínios de outras ciências. De um lado, acompanhando a tradição metafísica, a escola do direito natural indicava o fundamento do Direito na razão humana. De outro lado, amparado nas lições da filosofia cética, o positivismo jurídico apontava a vontade como o seu fundamento. Cada uma destas posições era reforçada diante da resposta dada a outras 02 (duas) questões. ${ }^{38}$

A primeira delas diz respeito à relação entre Direito e Moral. Para o jusnaturalismo, uma vez que a razão poderia acessar os princípios universais que devem pautar a conduta humana, os sistemas normativos (incluindose, aqui, o Direito) somente poderiam ser considerados válidos se fossem compatíveis com tais princípios. ${ }^{39} \mathrm{Se}$ todos os sistemas normativos podem ser identificados pela razão humana, ou seja, se todos eles decorrem de um único fundamento último, entre os sistemas jurídico e moral - e, portanto, entre o Direito e a Moral -, deve ser reconhecida uma conexão conceitual necessária (morality thesis), sendo artificial qualquer visão dualista.

Já para o positivismo jurídico, a validade de uma norma jurídica independeria de sua compatibilidade com outros sistemas normativos, em geral, e com a Moral, em particular. Deste modo, uma vez que os sistemas

\footnotetext{
${ }^{34}$ KELSEN, Hans [1941]. O Direito como Técnica Social Específica. In: KELSEN, Hans [1957]. O que é Justiça?. Trad. Luis Carlos Borges. São Paulo: Martins Fontes, 1998, p. 230.

${ }_{35}^{35}$ KELSEN, Hans [1960]. Teoria Pura do Direito. Trad. João Baptista Machado. 6a ed., São Paulo: Martins Fontes, 1998, p. 3.

${ }^{36}$ Idem, p. 113.

${ }^{37}$ HARTNEY, Michael [1991]. Introduction. In: KELSEN, Hans [1979]. General Theory of Norms. Oxford: Clarendon Press, 1991, p. xxi.

${ }^{38}$ PAULSON, Stanley [1998]. Introduction. In: PAULSON, Stanley et PAULSON, Bonnie L. (Org). Normativity and Norms. Critical Perspectives on Kelsenian Themes. Oxford: Clarendon Press, 1998, p. xxxi.

${ }^{39}$ STRUCHINER, Noel [2005]. Algumas "Proposições Fulcrais” Acerca do Direito: O Debate Jusnaturalismo vs. Positivismo. In: MAIA, Antonio Cavalcanti et alli (Org.). Perspectivas Atuais da Filosofia do Direito, Rio de Janeiro: Lumen Iuris, 2005, p. 400.
} 
normativos são construções arbitrárias da vontade humana, ${ }^{40}$ o sistema jusnormativo deve ser identificado através de suas fontes sociais, ${ }^{41}$ e não pela sua compatibilidade com outros sistemas normativos (separation thesis), devendo ser afirmada a autonomia conceitual do Direito em relação a outros sistemas normativos.

A segunda, por sua vez, diz respeito à natureza do Direito. Para o jusnaturalismo, a natureza do Direito era, sem dúvida, normativa. Uma vez que a razão poderia conhecer as normas que regulam a conduta humana, não seria admissível que esta (conduta) contrariasse aquela (norma). A norma é uma verdadeira ordem (leia-se: imperativo), coagindo a vontade humana a escolher o que a razão reconhece como praticamente necessário, ou seja, como bom. ${ }^{42}$ As regras do dever-ser obtidas pela razão configuravam verdadeiros imperativos, e estas normas eram, justamente, o seu objeto (normativity thesis).

Em sentido contrário, o positivismo jurídico anterior à Kelsen, ainda não completamente emancipado da Escola Histórica do Direito, ${ }^{43}$ reduzia o Direito à faticidade vigente nas relações sociais e negava sua dimensão normativa. Em última instância, toda ciência baseia-se no estudo de fatose, portanto, para o positivismo jurídico, a ciência do Direito deveria ter por objeto o comportamento do homem em sociedade (fatos empíricos) e nada mais. ${ }^{44} \mathrm{~A}$ definição do Direito dependeria, assim, exclusivamente da análise dos fatores sociais que permitiram sua

\footnotetext{
${ }^{40}$ Neste ponto, convém esclarecer que o objeto de estudo da filosofia moral divide-se, basicamente, em 03 (três) ramos: i) a ética normativa, que busca identificar construções filosóficas que estruturam sistemas normativos destinados a nortear a conduta humana; ii) a ética aplicada, que se ocupa de questões concretas e vitais da ação humana, forçando uma adaptação ou modificação dos sistemas éticos identificados pela ética normativa; e iii) a metaética, que tem por finalidade discutir se os fundamentos da moral são racionais ou sentimentais, isto é, se estamos veiculando conhecimento verdadeiro ou se estamos simplesmente dando vazão aos nossos sentimentos, emoções ou preferências. Note-se que o reconhecimento de sistemas éticos (ética normativa), ou de seu desenvolvimento (ética aplicada), não depende de uma postura metaética positiva (ou congitivista). Assim sendo, embora seja possível identificar, em qualquer sociedade, determinado sistema normativo ético (objeto da ética normativa), ou mesmo analisar seu desenvolvimento prático (ética aplicada), o fundamento último da moral, para os não-cognitivistas (e, também, para a maioria dos positivistas), é sempre de caráter irracional (postura metaética negativa). O ceticismo da posição positivista, como bem nota Alf Ross, "(...) não se refere à moral, mas sim à lógica do discurso moral; não se refere à ética, mas sim à metaética." Respectivamente: CARVALHO, Maria Cecília Maringoni de [2004]. Ética: uma Questão de Invenção ou de Descoberta ?. In: ROUANET, Luiz Paulo et alli (Org.). Razão Mínima. São Paulo: Unimarco, 2004, p. 12 e 13 et ROSS, Alf [1969]. El Concepto de Validez y Otros Ensayos. México DF: Distribuiciones Fontamara, 2001, p. 21.

${ }^{41}$ STRUCHINER, Noel [2005]. Algumas "Proposições Fulcrais" Acerca do Direito: O Debate Jusnaturalismo vs. Positivismo. In: MAIA, Antonio Cavalcanti et alli (Org.). Perspectivas Atuais da Filosofia do Direito, Rio de Janeiro: Lumen Iuris, 2005, p. 410.

${ }^{42}$ ABBAGNANO, Nicola [1971]. Dicionário de Filosofia. Trad. Alfredo Bosi. 2a ed., São Paulo: Martins Fontes, 1998, p. 545.

${ }^{43}$ A Escola Histórica do Direito surgiu na Alemanha no início do século XIX. Este movimento afirmava o sentido irracional da história (em contraposição à interpretação racionalista e universalista dos iluministas, em geral, e dos jusnaturalistas, em particular) e concentrava seus estudos na produção normativa de seu país. Suas vigorosas críticas contra o jusnaturalismo serviram de base epistemológica ao positivismo jurídico, embora apresente teses incompatíveis com este, como a crítica da centralização normativa nas mãos do Estado, a defesa do papel determinante dos costumes específicos da cultura de cada país (Volksgeist ou "espírito do povo") e o papel central da doutrina na sistematização do Direito. Cf.BOBBIO, Norberto [1969]. O Positivismo Jurídico - Lições de Filosofia do Direito. Trad. Márcio Pugliesi, Edson Bini e Carlos E. Rodrigues. São Paulo: Ícone, 1995, p. 45; DIMOULIS, Dimitri [2006]. Positivismo Jurídico - Introdução a uma Teoria do Direito e Defesa do Pragmatismo Jurídico-Político. São Paulo: Método, 2006, p. 70.

${ }^{44}$ KELSEN, Hans [1959]. Uma Teoria "Realista” y la Teoria Pura Del Derecho. In: Contribuiciones a la Teoría Pura del Derecho. México DF: Distribuciones Fontamara, 2003, p. 10.
} 
criação, e não de considerações valorativas sobre a conduta do homem em sociedade (facticity thesis). ${ }^{45}$

Estas posições sempre foram consideradas incompatíveis entre si. Ou o Direito era considerado (i.a.) um sistema normativo (i.b.) intrinsecamente relacionado com a Moral (posição jusnaturalista), ou (ii.a.) o encadeamento de fatos sociais (ii.b.) sem qualquer conexão necessária com os demais sistemas normativos (posição positivista). Qualquer busca por uma terceira via estava fadada ao insucesso.

Eis, justamente, o desafio lançado por Kelsen. De um lado, sua Teoria Pura do Direito vai aceitar a tese da separação, afirmando, em consonância com a tradição positivista, que o Direito não mantém qualquer relação necessária com a Moral. Este é, sem dúvida, o seu ponto de partida. Todavia, em frontal ruptura com esta mesma tradição, Kelsen vai assumir uma posição até então exclusivamente jusnaturalista: a de que o Direito possui uma dimensão normativa. ${ }^{46}$

Para Kelsen, ${ }^{47}$ esta dimensão normativa do Direito encontra o seu fundamento filosófico o dualismo metodológico ${ }^{48}$ da Escola Neo-Kantiana de Marburg, ${ }^{49}$ mais especificamente na distinção entre (i) mundo dos fatos (ser), objeto das ciências naturais e explicados nos termos da causalidade, e (ii) mundo dos valores (deverser), objeto das ciências do espírito (leia-se: culturais) e explicados nos termos da imputação de sentido aos atos ou fatos naturais pela vontade humana.

Assim, para a Teoria Pura do Direito, o ato que cria uma norma jurídica é, sem dúvida, um fato ( "is-fact”, Seinstatsache). ${ }^{50}$ Todavia, o sentido objetivo deste ato, isto é, a norma jurídica (dever-ser), possui uma realidade autônoma na esfera cultural (ser). Ao conciliar a separação entre o Direito e a Moral (separation thesis) com a dimensão normativa do Direito (normativity thesis), sua Teoria Pura do Direito funcionou como um meio

\footnotetext{
${ }^{45}$ Estes 2 (dois) pares de teses também podem ser descritos nos termos da distinção entre ser (is, Sein) e dever-ser (ought, Sollen). Segundo Stanley Paulson, "the distinction is systematically ambiguous; on one reading, is' and 'ought' take their values from the first pair of thesis, on another reading, from the second pair. Thus, from the standpoint of the separation and morality theses, norms of the law belong to 'is', and norms or morality, to 'ought', while, from the standpoint of the normativity and facticity theses, legal norms belong to 'ought', and concatenations of fact, which are constrasted with legal norms, to is." Paulson, Stanley [1998]. Introduction. In: PAULSON, Stanley et PAULSON, Bonnie L. (Org). Normativity and Norms. Critical Perspectives on Kelsenian Themes. Oxford: Clarendon Press, 1998, p. xxxi.

${ }^{46}$ Todavia, enquanto Kelsen entendia que o Direito possui uma dimensão normativa, a tradição jusnaturalista afirmava que o Direito éum sistema normativo.

${ }^{47}$ KELSEN, Hans [1933]. The Pure Theory of Law, "Labandism” and Neo-Kantianism. A Letter to Renato Treves. In: PAULSON, Stanley et PAULSON, Bonnie L. (Org). Normativity and Norms. Critical Perspectives on Kelsenian Themes. Oxford: Clarendon Press, 1998, p. 27-33.

${ }^{48}$ Esta dualidade entre natureza e sociedade foi, justamente, o objeto de análise do item precedente, para o qual, diante de eventuais dúvidas, remete-se o leitor.

49 A deminada Escola Neo-Kantiana de Marburg tinha como seu maior expoente o filósofo Hermann Cohen (1842-1918). Inclusive, ao que parece, um dos seus livros, Ética da Vontade Pura ("Ethik des reinen Willens") serviu de inspiração para a denominação da teoria jurídica de Hans Kelsen. In: MÉTALL, Rudolf Aladár [1976]. Hans Kelsen - Vida y Obra. Trad. Javier Esquivel. Mexico DF: Instituto de Investigaciones Jurídicas - UNAM, 1976, p. 15.

${ }^{50}$ KELSEN, Hans [1960]. Pure Theory of Law. Trad. Max Knight. Berkeley: University of California Press, 1967, p. 211.
} 
termo $^{51}$ entre as tradições jusnaturalistas e juspositivistas, tornando possível a explicação do Direito de forma independente dos fatos que the deram origem. ${ }^{52}$

Através destas referências metodológicas, Kelsen acaba por instaurar uma "dupla pureza" ${ }^{\text {"3 }}$ na ciência do Direito. De um lado, a adesão à tese da separação entre o Direito e a Moral permite uma pureza axiológica (ou valorativa) da ciência do Direito: ao assumir uma posição exclusivamente descritiva do Direito, a ciência do Direito passa a ter por objeto específico o Direito Positivo (ou Real), e não o Direito Ideal, objeto da política. ${ }^{54}$ Note-se, todavia, que sua Teoria Pura propõe-se a delimitar o Direito no que diz respeito aos valores, e não eliminar $r^{55}$ toda e qualquer consideração moral sobre ou a partirdo Direito. ${ }^{56}$

De outro, a adesão à tese da normatividade, permite que a Teoria Pura do Direito alcance uma pureza sociológica. Neste passo, sem negar a possibilidade de uma ou mais ciências que estude o Direito de acordo com seus fatores sociais, ${ }^{57}$ a sua ciência do Direito pretende ser uma Teoria Pura do Direito Positivo, e não uma Teoria do Direito Puro, ${ }^{58}$ ou seja, de um

Direito desligado da realidade. ${ }^{59}$

Assim, segundo o próprio Kelsen:

\footnotetext{
${ }^{51}$ Note-se, aqui, que Kelsen expressamente caracterizou sua teoria como um meio-termo (middle-way, Mittelweg) entre as tradições jusfilosóficas. KELSEN, Hans [1960]. Pure Theory of Law. Trad. Max Knight. Berkeley: University of California Press, 1967 , p. 211.

${ }^{52}$ PAULSON, Stanley [1998]. Introduction. In: PAULSON, Stanley et PAULSON, Bonnie L. (Org). Normativity and Norms. Critical Perspectives on Kelsenian Themes. Oxford: Clarendon Press, 1998, p. xxxii.

${ }^{53}$ RAZ, Joseph [1981]. The Purity of the Pure Theory. In: PAULSON, Stanley et PAULSON, Bonnie L. (Org). Normativity and Norms. Critical Perspectives on Kelsenian Themes. Oxford: Clarendon Press, 1998, p. 238.

${ }^{54}$ KELSEN, Hans [1945]. Teoria Geral do Direito e do Estado. Trad. Luís Carlos Borges. 3a ed., São Paulo: Martins Fontes, 1998, p. xxix.

${ }^{55}$ LOSANO, Mario [1976]. Introdução. In: KELSEN, Hans [1960]. O Problema da Justiça. Trad. João Baptista Machado. $3^{a}$ ed., São Paulo: Martins Fontes, 1998, p. xiv.

56 "Na medida em que, na aplicação da lei, para além da necessária fixação da moldura dentro da qual se tem de manter o ato a pôr, possa ter ainda lugar uma atividade cognoscitiva do órgão aplicador do Direito, não se tratará de um conhecimento do Direito positivo, mas de outras normas que, aqui, no processo da criação jurídica, podem ter sua incidência: normas de Moral, normas de Justiça, juízos de valor sociais que costumamos designar por expressões correntes como bem comum, interesse do Estado, progresso etc." KELSEN, Hans [1960]. Teoria Pura do Direito. Trad. João Baptista Machado. 6a ed., São Paulo: Martins Fontes, 1998 , p. 393.

57 " The law may be the object of different sciences; the Pure Theory of Law has never claimed to be the only possible or legitimate science of law. Sociology of law and history of law are others. They, together with the structural analysis of law, are necessary for a complete understanding of the complex phenomenom of law." KELSEN, Hans [1948]. Law, State and Justice in the Pure Theory of Law. In: KELSEN, Hans [1957]. What is Justice? - Justice, Law and Politics in the Mirror of Science. New Jersey: The Lawbook Exchange, 2000, p. 294.

58 "La despolitización que la teoría pura del derecho exige se refiere a la ciencia del derecho no a su objeto, el derecho. El derecho no puede ser separado de la política, pues es esencialmente un instrumento de la política. Tanto su creación como su aplicación son funciones políticas, es decir, funciones determinadas por juicios de valor. Pero la ciencia del derecho puede y debe ser separada de la política si es que pretende valer como ciencia.(...) La teoría pura del derecho és una teoría pura del derecho, no la teoría de un derecho puro (...)” KELSEN, Hans [1953]. ¿Que és la Teoría Pura del Derecho? Trad. Ernesto Garzón Valdéz. Mexico DF: Distribuiciones Fontamara, 1991, p. 29 e 30.

${ }^{59}$ LOSANO, Mario [1966]. Introdução. In: KELSEN, Hans [1960]. O Problema da Justiça. Trad. João Baptista Machado. $3^{a}$ ed., São Paulo: Martins Fontes, 1998, p. xvi.
} 
quando esta doutrina é chamada de 'teoria pura do Direito', pretende-se dizer com isso que ela está sendo conservada livre de elementos estranhos ao método específico de uma ciência cujo único propósito é a cognição do Direito, e não a sua formação. ${ }^{60}$

Se a ciência do Direito quiser se libertar das demais esferas do conhecimento e ver respeitada a sua autonomia, ela precisa delimitar o seu objeto com a máxima precisão. ${ }^{61}$ Logo, continua Kelsen:

quando a Teoria Pura empreende delimitar o conhecimento do Direito em face [de outras] disciplinas, fá-lo não por ignorar ou, muito menos, por negar essa conexão, mas porque intenta evitar um sincretismo metodológico que obscurece a essência da ciência jurídica e dilui os limites que the são impostos pela natureza do seu objeto. ${ }^{62}$

Impõe-se reconhecer que a Teoria Pura do Direito de Hans Kelsen sempre buscou delimitar, com clareza, o seu objeto de cognição. ${ }^{63}$ Em que pese as suas constantes mudanças e evoluções, esta sempre teve um objetivo bem definido, desde sua obra inaugural ${ }^{64}$ até sua obra póstuma ${ }^{65}$ : estabelecer a norma jurídica como objeto da ciência do Direito. Logo, seu objeto não são os fatos sociais ou a valoração dada a estes fatos, ${ }^{66}$ mas sim uma esfera autônoma de sentido: a norma jurídica. O que transforma um fato natural num ato jurídico (lícito ou ilícito) não é a sua facticidade, não é o seu ser natural, isto é, o seu ser tal como determinado pela lei da causalidade e encerrado no sistema da natureza, mas o sentido objetivo que está ligado a esse ato, a significação que ele possui. $^{67}$

Assim, quando a Teoria Pura do Direito, como específica ciência do Direito, concentra a sua visualização sobre as normas jurídicas, e não sobre fatos da ordem do ser (quer dizer: não a dirige para o querer ou para o representar das normas jurídicas, mas para as normas jurídicas como conteúdo de sentido - querido ou representado), ela abrange e apreende quaisquer fatos apenas na medida em que estes fatos são o conteúdo de

\footnotetext{
${ }^{60}$ KELSEN, Hans [1945]. Teoria Geral do Direito e do Estado. Trad. Luís Carlos Borges. 3a ed., São Paulo: Martins Fontes, 1998, p. Xxviii.

${ }^{61}$ KELSEN, Hans [1934]. Introduction to the Problems of Legal Theory: A Translation of the First Edition of the Reine Rechtslehre or Pure Theory of Law. Trad. Stanley L. Paulson, Oxford: Clarendon Press, 1997, p. 8.

${ }^{62}$ KELSEN, Hans [1960]. Teoria Pura do Direito. Trad. João Baptista Machado. 6a ed., São Paulo: Martins Fontes, 1998, p. 2.

63 "The Pure Theory of Law seeks to delimit cleary the object of its congition". In KELSEN, Hans [1934]. Introduction to the Problems of Legal Theory: A Translation of the First Edition of the Reine Rechtslehre or Pure Theory of Law. Trad. Stanley L. Paulson, Oxford: Clarendon Press, 1997, p. 8.

${ }^{64}$ "La jurisprudencia, la ciencia del derecho, figura, décimos, entre las disciplinas normativas (...) El caráter normativo de la jurisprudencia se manifesta (...) por cuanto que versa sobre normas (...) de las quales tiene que derivar sus conceptos jurídicos especiales." KELSEN, Hans [1911]. Problemas Capitales de la Teoria Jurídica del Estado. Trad. Wenceslao Roces. México D.F., Editorial Porrua, 1987, p. 6.

65 'Nella lingua tedesca non cé neanche un nome diverso da termine logica', come nome di una scienza, per le norme che costituiscono l'oggetto della scienza che descrive queste norme, come invece esiste il nome 'morale' per le norme che costituiscono l'oggetto dell'etica e il nome 'diritto' per le norme che costituiscono l'oggetto della scienza del diritto." KELSEN, Hans [1979]. Teoria Generale delle Norme. Trad. Mirella Torre. Torino: Giulio Einaudi, 1985, p. 3.

${ }^{66}$ De acordo com o próprio Kelsen, a pureza de sua teoria é assegurada em 2 (duas) direções: i) "it is to be secured against the claims of a so-called 'sociological' point of view, which uses the methods of the causal sciences to appropriate the law as a part of nature."; ii) "to be secured against the claims of the natural law theory, which (... ) takes legal theory out of the realm of positive legal norms and into the realm of ethico-political postulates." KELSEN, Hans [1923]. Foreword to the Second Printing of Main Problems in the Theory of Public Law. In: PAULSON, Stanley et PAULSON, Bonnie L. (Org). Normativity and Norms. Critical Perspectives on Kelsenian Themes. Oxford: Clarendon Press, 1998, p. 3-4.

${ }^{67}$ KELSEN, Hans [1960]. Teoria Pura do Direito. Trad. João Baptista Machado. 6aa ed., São Paulo: Martins Fontes, 1998, p. 4.
} 
normas jurídicas, quer dizer, na medida em que são determinados por normas jurídicas. ${ }^{68}$ Eis, portanto, o objeto de sua teoria jurídica.

\section{NORMA JURÍDICA: EVOLUÇÃO CONCEITUAL}

Definido o objeto da ciência jurídica, a norma jurídica (apenas uma das dimensões do Direito, e não o Direito como um todo), Kelsen iria enfrenta um outro desafio: apresentar um conceito de norma jurídica compatível com as exigências de pureza por ele mesmo lançadas. Essa tarefa foi desempenhada naquelas que podem ser consideradas as principais obras da Teoria Pura do Direito, a saber: i) Problemas Fundamentais da $\underline{\text { Teoria do Direito Público, }}{ }^{69}$ de 1911; ii) $\underline{\text { Teoria Geral do Estado, }}{ }^{70}$ de 1925 ; iii) $\underline{\text { Teoria Pura do Direito }}$ (1ª Edição), ${ }^{71}$ de 1934; iv) Teoria Geral do Direito e do Estado, ${ }^{72}$ de 1945; v) Teoria Pura do Direito (2a Edição), ${ }^{73}$ de 1960; e vi) $\underline{\text { Teoria Geral das Normas, }}{ }^{74}$ obra póstuma editada e publicada em 1979.

Logo na obra inaugural da Teoria Pura do Direito, Kelsen iria questionar a doutrina tradicional que enxergava a norma jurídica como um imperativo, como uma ordem estatal dirigida ao súdito. Isto porque, essa

\footnotetext{
${ }^{68}$ Idem, p. 113

${ }^{69}$ Publicação original: KELSEN, Hans [1911]. Hauptprobleme der Sttatsrechtslehre, entwickelten aus der Lehre vom Rechtssatze. Tübingen: JCB Mohr, 1911, 719p. O presente estudo teve por base as traduções para o espanhol e para o italiano. Respectivamente: KELSEN, Hans [1911]. Problemas Capitales de la Teoria Jurídica del Estado. Trad. Wenceslao Roces. México D.F., Editorial Porrua, 1987 et KELSEN, Hans [1911]. Problemi Fondamentali della Dottrina Del Diritto Pubblico. Trad. Agostino Carrino. Napoli: Edizioni Scientifiche Italiane, 1997.

${ }^{70}$ Publicação original: KELSEN, Hans [1925]. Allgemeine Staatslehre. Berlin: Julius Springer, 1925, 433p. O presente estudo teve por base a tradução para o idioma espanhol: KELSEN, Hans [1925]. Teoría General del Estado. Trad. Luis Legaz Lacambra. Barcelona: Editorial Labor, 1934.

${ }^{71}$ Publicação original: KELSEN, Hans [1934]. Reine Rechtslehre - Einleitung in die rechtswissenschaftliche Problematik. Leipzig und Wien: Franz Deuticke, 1934, 236p. O presente estudo teve por base a tradução para a língua inglesa: KELSEN, Hans [1934]. Introduction to the Problems of Legal Theory: A Translation of the First Edition of the Reine Rechtslehre or Pure Theory of Law. Trad. Stanley L. Paulson, Oxford: Clarendon Press, 1997.

${ }^{72}$ Publicação original: KELSEN, Hans [1945]. General Theory of Law and State. Trad. Anders Wedberg. Cambridge: Harvard University Press, 1945, 516p. O presente estudo teve por base a edição original, bem como as traduções para o português e espanhol, respectivamente: KELSEN, Hans [1945]. General Theory of Law and State. 2a ed., Trad. Anders Wedberg. Cambridge: Harvard University Press, 1949; KELSEN, Hans [1945]. Teoria Geral do Direito e do Estado, Trad. Luis Carlos Borges. 3a ed., São Paulo: Martins Fontes, 1998 e KELSEN, Hans [1945]. Teoria General del Derecho y del Estado. Trad. Eduardo García Máynez. Mexico D.F.: Editorial Porrua, 2005.

${ }^{73}$ Publicação original: KELSEN, Hans [1960]. Reine Rechtlehre - Mit einem Anhang: Das Problem der Gerechtigkeit. Zweite, völlig neu bearbeitete und erweiterte Auflage. Wien: Franz Deuticke, 1960, 534 p. A base do presente estudo foi formada a partir das traduções para o português, inglês e espanhol, respectivamente: KELSEN, Hans [1960]. Teoria Pura do Direito. Trad. João Baptista Machado. 6a ed., São Paulo: Martins Fontes, 1999; KELSEN, Hans [1960]. Pure Theory of Law. Trad. Max Knight. Berkeley: University of California Press, 1967 e KELSEN, Hans [1960]. Teoria Pura del Derecho. Trad. Roberto Vernengo. Mexico D.F.: Editorial Porrua, 2005.

${ }^{74}$ Publicação original: KELSEN, Hans [1979]. Allgemeine Theorie der Normen - Im Auftrag des Hans Kelsen-Instituts aus dem Nachlaß herausgegeben von Kurt Ringhofer und Robert Walter. Wien: Manz, 1979, 362p. O presente estudo teve por base as traduções para os idiomas inglês, italiano e espanhol, respectivamente: KELSEN, Hans [1979]. General Theory of Norms. Trad. Michel Hartney. Oxford: Clarendon Press, 1991; KELSEN, Hans [1979]. Teoria Generale delle Norme. Trad. Mirella Torre. Torino: Giulio Einaudi, 1985 e KELSEN, Hans [1979]. Teoría General de las Normas. Trad. Hugo Carlos Delory Jacobs. Mexico DF: Trillas, 1994.
} 
concepção decorria de um "lamentável antropomorfismo" 75 na construção dos conceitos científicos. Uma ordem pressupõe uma vontade, o que, em sede estritamente teórica, é uma ficção insustentável, já que o Estado não é dotado de uma existência psicofísica semelhante aos dos seres humanos.

Assim é que, na obra de 1911, a norma jurídica foi apresentada como um juízo hipotético, de sorte que a norma jurídica teria, ao contrário do que sustentava a teoria jurídica tradicional, uma estrutura condicional, ligando uma condição (ou causa) a uma conseqüência (ou efeito). Sob o ponto de visa formal, toda e qualquer norma jurídica possuiria, na verdade, uma estrutura única, podendo ser sempre reconstruída nos termos de uma proposição jurídica. Outrossim, o reconhecimento da sanção como um elemento integrante da norma jurídica denotaria que a mesma tem por função criar uma obrigação para o próprio Estado, e não impor uma determinada conduta aos indivíduos. Com estas modificações teóricas, o Direito Positivo fora concebido, pela primeira vez, como o conjunto de normas que regulam o poder coercitivo do Estado.

Na obra de 1925, a proposta inicial ganha complexidade, pois a estrutura condicional da proposição jurídica poderia ser desdobrada numa série de proposições parciais, representadas por 2 (duas) espécies de normas, das quais apenas a primeira teria relevância para a ciência do Direito: i) as normas primárias, que estabelecem a condição para o ato coercitivo (" $M\left[\right.$ ou $\left.M^{0}\right]+E$, deve ser $Z \rightarrow M^{\prime}$ ); e ii) as normas secundárias, cujo o conteúdo é a condição ou a série de condições que não têm como conseqüência um ato coercitivo, expressa através da conduta devida para evitaro ato coercitivo ("faça X!; não faça X!').

Além disto, Kelsen reconheceu que o Direito também poderia ser analisado sob uma perspectiva dinâmica. Assim, ao lado da concepção estática, que parte da análise da ordem jurídica já acabada e orientada pelo ato coercitivo, o Direito poderia ser descrito como uma função de criação jurídica, sendo possível afirmar que todas as "funções" estatais estão inseridas numa estrutura hierárquica de diversos graus de criação jurídica, de sorte que cada uma das "funções" de criação limita e está limitada pelo exercício de uma outra "função". Dispostas de modo escalonado, as normas do nível superior delimitam um fato que constitui a criação do Direito num grau inferior, de modo que até mesmo os atos de individualização devem ser reconhecidos como normas jurídicas.

Já na obra de 1934 aparece, pela primeira vez, a definição da norma jurídica como o "sentido objetivo de um fato". Esta idéia, introduzida na obra de 1925 apenas para justificar a impossibilidade do ilícito estatal, agora assume uma posição fundamental na sua teoria jurídica: se antes a norma jurídica apenas conferia o sentido objetivo a um fato natural, a partir de agora é, ela mesma, o sentido objetivo atribuído a outro fato por uma outra norma jurídica.

Com esta inovação teórica, também foi possível conferir um tratamento unitário à sua teoria jurídica,

\footnotetext{
${ }^{75}$ KELSEN, Hans [1911]. Problemas Capitales de la Teoría Jurídica del Estado. Trad. Wenceslao Roces. 2a ed., Mexico DF: Editorial Porua, 1987, p. 57.
} 
composta por 2 (duas) parte: i) a estática jurídica; e ii) a dinâmica jurídica. De fato, se até então ambas as partes apresentavam aspectos incompatíveis e contraditórios, a partir de agora estas dimensões da realidade jurídica poderiam ser reduzidas a uma noção unitária, pois, ao mesmo tempo, a norma jurídica (i) “ê" o sentido objetivo de um fato natural, porque recebe seu significado de uma outra norma jurídica, e (ii) "confere" o sentido objetivo a outro fato natural, porque constitui um esquema de interpretação.

A obra de 1945, por seu turno, finalmente esclareceu que normas jurídicas e proposiçóes jurídicas formam realidades distintas: i) as primeiras são o produto da função de criação jurídica; e ii) as segundas são os enunciados formulados pela ciência jurídica sobre as normas jurídicas. Com isso, o viés reconstrutivista da Teoria Pura do Direito ficou definitivamente prejudicado em favor de uma formulação passiva, meramente descritiva, em que a ciência jurídica nada reconstrói ou reformula, mas apenas descreve seu objeto.

Outrossim, neste momento foi apresentada a tese de que as normas constitucionais são meras partes das normas gerais, e teriam por finalidade inserir em todas as normas gerais uma "matéria constitucional", designada como cláusula "se". Esta cláusula indicaria que, além da função de verificar a ocorrência efetiva da condição de fato prevista pela norma jurídica (quaestio facti), o órgão aplicador do Direito também deve verificar se a norma geral a ser aplicada é válida, se ela foi criada do modo previsto pela Constituição (quaestio juris).

Não obstante, não havia, até então, uma resposta satisfatória para alguns graves problemas da Teoria Pura do Direito, a saber: i) como compatibilizar as funções de regular os atos coercitivos e a função de regular a criação jurídica?; ii) qual é a natureza da obrigação criada pela norma jurídica à autoridade responsável por aplicar a sanção? Estas questões têm um ponto em comum: a noção de que a norma jurídica cria uma obrigação (ou dever) de aplicar a sanção dirigida à autoridade competente, ponto este que sofreria uma profunda revisão na obra de 1960 .

Esta revisão tem como ponto central a noção de que a norma jurídica não cria uma obrigação ao Estado. Na verdade, quando uma norma jurídica prevê a aplicação de uma conseqüência (ou efeito) a uma condição (ou causa), ela está atribuindo a uma pessoa um poder jurídico, ou seja, uma autorização para a aplicação da sanção.

Além disso, a obra de 1960 introduziu um acréscimo relevante na definição da norma jurídica. Mais do que o mero sentido de um ato qualquer, a norma jurídica passa a ser definida como o sentido objetivo de um ato de vontade. Com esta alteração, a sua definição passa a apresentar 2 (duas) partes: a norma jurídica é (i) o sentido objetivo de um ato e, por sua vez, este ato é (ii) um ato de vontade. De um lado, a idéia de que a norma jurídica, ao mesmo tempo, "é e "confere" um sentido objetivo a um fato (ou ato) já havia sido incorporada à Teoria Pura do Direito na obra de 1934. Para ser entendido como norma jurídica, o sentido de um fato deve ser avalizado por uma outra norma jurídica. Pouco importa, assim, outros sentidos possíveis ou mesmo o sentido eventualmente atribuído por outras fontes: apenas o sentido conferido por uma outra norma jurídica qualifica um determinado 
sentido como norma jurídica. De outro lado, a segunda parte da definição indica, de forma inédita, que um sentido objetivo avalizado por uma norma jurídica somente pode ser conferido a um ato de vontade. E os atos de vontade, por sua vez, têm por finalidade (i) autorizar, (ii) permitir ou (iii) prescrever (comandar, ordenar) uma determinada conduta.

Outro importante avanço da obra de 1960 é a apresentação de elementos suficientes para a distinção entre a estática jurídica a dinâmica jurídica. Logo, se a norma jurídica pode ser definida de forma integral como o sentido objetivo de um ato de vontade, para a teoria dinâmica esta vontade prescreve ou permite uma conduta, através da imposição de uma sanção dirigida contra a conduta contrária, e para a teoria dinâmica esta mesma vontade confere a uma outra manifestação de vontade a natureza de norma jurídica, através da atribuição de um poder jurídico.

Todavia, a esta obra deixou 2 (duas) importantes perguntas. A primeira delas é a seguinte: o que significa dizer que uma norma é o sentido de um ato de vontade? A resposta dada pela obra de 1979 é que haverá uma norma sempre que haja um ato de vontade com pretensóes normativas, ou seja, sempre que uma pessoa prescrever um estado ideal de conduta (dever-ser e o seu conteúdo) a um certo destinatário. Já a qualificação desta norma como norma jurídica (leia-se: a sua validade dentro de um ordenamento específico, a sua específica existência) pressupõe que o sentido subjetivo do respectivo ato de vontade seja reconhecido (ou autorizado) por uma outra norma jurídica.

Já a segunda pergunta indaga se as diversas funções são exercidas por uma única norma jurídica ou por normas jurídicas distintas? A reposta encontrada na obra póstuma de Kelsen é que, enquanto a função prescritiva é veiculada por uma norma primária, a função de conferir um poder jurídico, através da possibilidade de aplicação de um ato coercitivo, é materializada por uma norma secundária.

Além disso, Kelsen efetuou alguns ajustes na sua teoria da norma fundamental (que passa a ser entendida como uma ficção) e incluiu a derrogação entre as funções reconhecidas às normas jurídicas. Enquanto, a norma básica passa a ser concebida como o sentido objetivo de um ato de vontade fictício, meramente pensado, dotada de uma finalidade exclusivamente cognitiva, a derrogação é entendida como uma função de extinguir prescrições e permissões criadas por outras normas jurídicas.

\section{POR UMA DEFINIÇÃO DE NORMA JURÍDICA NA TEORIA PURA DO DIREITO}

Feitas esta breve digressão histórica, a norma jurídica pode ser definida no estágio final de desenvolvimento da Teoria Pura do Direito como o sentido de um ato de vontade que, reconhecido por outra norma jurídica, veicula um dever-ser composto por (a) uma norma primária, que cria um dever jurídico e tem por conteúdo (i) a prescrição ou (ii) a permissão de uma determinada conduta ou, ainda, (iii) a derrogação de uma 
outra norma jurídica, e (b) uma norma secundária, que cria um poder jurídico e tem por conteúdo (iv) a autorização para a aplicação de um ato coercitivo.

Dizer que a norma jurídica é o "sentido de um ato de vontade que veicula um dever-ser" indica que não é qualquer ato que pode assumir a natureza de uma norma jurídica, mas apenas um ato de vontade que, pretendido pelo emissor e compreendido pelo destinatário, gera uma situação de sujeição.

"Autorizado por outra norma jurídica" porque, se todo e qualquer ato de vontade que veicula um deverser gera uma norma, a sua qualificação como norma jurídica pressupõe que o sentido subjetivo desejado pelo emissor seja compatível com outra norma jurídica.

A expressão "um dever-ser composto por uma norma primária (...) e uma norma secundária” demonstra que há, em qualquer situação, 2 (dois) destinatários da norma jurídica, a saber: i) um indireto, que é a pessoa sujeita ao ato coercitivo, caso pratique a conduta contrária daquela descrita; ii) um direto, que é o agente estatal responsável pela aplicação do ato coercitivo.

"Norma primária que cria um dever jurídico" porque, de um lado, a norma jurídica cria uma obrigação para o súdito através da estipulação de uma sanção (conseqüência ou efeito) para a realização da conduta contrária àquela descrita por ela (condição ou causa).

"Norma secundária que cria um poder jurídico e tem por conteúdo (iv) a autorização para a aplicação de um ato coercitivo" porque, de outro lado, a norma jurídica não cria uma obrigação de aplicação do ato coercitivo, mas uma mera autorização, pois não há, em princípio, uma sanção prevista para o caso da não aplicação. Caso haja uma outra sanção estabelecida para a sua não aplicação, a sua aplicação será o conteúdo de uma outra norma primária que obriga o seu destinatário a fazê-lo, tornando-o passível da aplicação de um outro ato coercitivo pelo destinatário de outra norma secundária.

Já a expressão "tem por conteúdo (i) a prescrição ou (ii) a permissão de uma determinada conduta" indica que a norma primária pode (i) regulamentar uma conduta de forma ativa, quando a um indivíduo é determinada a realização ou a omissão de um determinado ato, ou (ii) regulamentar uma conduta de uma forma passiva, quando se limita a incidência de uma norma proibitiva de determinada conduta através de uma outra norma, que permite a conduta proibida ou, ainda quando uma conduta, não sendo proibida pelo ordenamento jurídico, também não é positivamente permitida por uma norma delimitadora do âmbito de validade de outra norma proibitiva.

A expressão "tem por conteúdo (...) (iii) a derrogação de uma outra norma jurídica" demonstra que o conteúdo do ato de vontade também pode ter por finalidade fulminar a validade de uma outra norma jurídica, estatuindo um dever-ser negativo.

Esta definição completa apresenta alguns problemas, por óbvio, notadamente por incorporar elementos 
da obra póstuma de 1979, obra esta baseada em anotações de Kelsen e que, por isso, não receberam um tratamento definitivo pelo próprio autor. No entanto, pode servir de um guia para futuros estudos dos interessados pelo pensamento de Hans Kelsen.

\section{CONSIDERAÇÕES FINAIS}

Por necessidade de síntese didática, verifica-se que as idéias desenvolvidas no presente texto podem ser condensadas em proposições objetivas, a saber:

1. Kelsen iria dedicou toda sua vida ao projeto de desenvolver uma teoria jurídica pura, isto é, purificada de toda a ideologia política e de todos os elementos da ciência natural.

2. Embora formem uma única realidade fática, natureza e sociedade correspondem a diferentes sistemas. Por isso, são objetos que demandam a construção de um instrumental teórico específico para seu estudo.

3. O mundo natural corresponde ao mundo físico. Suas relações são determinadas pelo princípio da causalidade, o qual o pensamento humano meramente constata.

4. Já o mundo cultural tem natureza normativa. Suas relações são explicadas através da imputação, onde uma vontade atribui determinado sentido ao fato natural.

5. Embora o ato que cria uma norma jurídica seja um fato, o seu sentido objetivo, isto é, a norma jurídica (dever-ser) possui uma realidade autônoma na esfera cultural.

6. A adesão à tese da separação (entre o Direito e a Moral) permite uma pureza axiológica (ou valorativa) da ciência do Direito.

7. De outro lado, a adesão à tese da normatividade (o Direito não se resume a um fato social), permite que a Teoria Pura do Direito alcance uma pureza sociológica.

8. Esta "esfera autônoma de sentido", mais especificamente, a norma jurídica é, para Hans Kelsen, o objeto da Ciência do Direito.

9. Norma jurídica é o sentido de um ato de vontade que, reconhecido por outra norma jurídica, veicula um dever-ser composto por (a) uma norma primária, que cria um dever jurídico e tem por conteúdo (i) a prescrição ou (ii) a permissão de uma determinada conduta ou, ainda, (iii) a derrogação de uma outra norma jurídica, e (b) uma norma secundária, que cria um poder jurídico e tem por conteúdo (iv) a autorização para a aplicação de um ato coercitivo. 


\title{
THE DELIMITATION OF LEGAL SCIENCE AND THE DEFINITION OF LEGAL NORM IN THE PURE THEORY OF LAW
}

\begin{abstract}
By (i) establishing the status of the cultural sciences as opposed to the natural sciences, and by (ii) distinguishing Law from others social phenomenas, Hans Kelsen has delimited the Legal Norm as the object of Legal Science. From that point, he introduced a definition of legal norm which suffered successive conceptual changes for about half a century.
\end{abstract}

Keywords: Hans Kelsen; Legal Science; Definition of its Subject; Legal Norm; Definition.

\section{BIBLIOGRAFIA}

ABBAGNANO, Nicola [1971]. Dicionário de Filosofia. Trad. Alfredo Bosi. 2a ed., São Paulo: Martins Fontes, 1998.

BOBBIO, Norberto [1969]. O Positivismo Jurídico - Lições de Filosofia do Direito. Trad. Márcio Pugliesi, Edson Bini e Carlos E. Rodrigues. São Paulo: Ícone, 1995.

CARVALHO, Maria Cecília Maringoni de [2004]. Ética: uma Questão de Invenção ou de Descoberta?. In: ROUANET, Luiz Paulo et alli (Org.). Razão Mínima. São Paulo: Unimarco, 2004.

DIMOULIS, Dimitri [2006]. Positivismo Jurídico - Introdução a uma Teoria do Direito e Defesa do PragmatismoJurídico-Político. São Paulo: Método, 2006.

HARTNEY, Michael [1991]. Introduction. In: KELSEN, Hans [1979]. General Theory of Norms. Oxford: Clarendon Press, 1991.

KELSEN, Hans [1911]. Hauptprobleme der Sttatsrechtslehre, entwickelten aus der Lehre vom Rechtssatze. Tübingen: JCB Mohr, 1911.

[1911]. Problemi Fondamentali della Dottrina Del Diritto Pubblico. Trad. Agostino Carrino. Napoli: Edizioni Scientifiche Italiane, 1997.

[1911]. Problemas Capitales de la Teoría Jurídica del Estado. Trad. Wenceslao Roces. 2a ed., Mexico DF: Editorial Porua, 1987.

[1923]. Foreword to the Second Printing of Main Problems in the Theory of Public Law. In: PAULSON, Stanley et PAULSON, Bonnie L. (Org). Normativity and Norms. Critical Perspectives on Kelsenian Themes. Oxford: Clarendon Press, 1998.

[1925]. Allgemeine Staatslehre. Berlin: Julius Springer, 1925.

[1925]. Teoría General del Estado. Trad. Luis Legaz Lacambra. Barcelona: Editorial Labor, 1934.

[1933]. La Teoría Pura del Derecho. Trad. Jorge G. Tijerina. 2a ed., Buenos Aires: Posada, 1941.

[1933]. The Pure Theory of Law, "Labandism" and Neo-Kantianism. A Letter to Renato Treves. In.: PAULSON, Stanley et PAULSON, Bonnie L. (Org). Normativity and Norms. Critical Perspectives on Kelsenian Themes. Oxford: Clarendon Press, 1998.

[1934]. Reine Rechtslehre - Einleitung in die rechtswissenschaftliche Problematik Leipzig und Wien: Franz Deuticke, 1934. 
[1934]. Introduction to the Problems of Legal Theory: A Translation of the First Edition of the Reine Rechtslehre or Pure Theory of Law. Trad. Stanley L. Paulson, Oxford: Clarendon Press, 1997.

[1941]. The Law as Specific Technique. In.: [1957]. What is Justice? - Justice, Law and Politics in the Mirror of Science. New Jersey: The Lawbook Exchange, 2000.

[1941]. O Direito como Técnica Social Específica. In..: [1957]. O que é Justiça?. Trad. Luis Carlos Borges. São Paulo: Martins Fontes, 1998.

[1944]. Peace Through Law. 3a ed., New Jersey: The Lawbook Exchange, 2000.

1945.

[1945]. General Theory of Law and State. Trad. Anders Wedberg. Cambridge: Harvard University Press,

[1945]. Teoria Geral do Direito e do Estado, Trad. Luis Carlos Borges. 3a ed., São Paulo: Martins Fontes, 1998.

Porrua, 2005

[1945]. Teoria General del Derecho y del Estado. Trad. Eduardo García Máynez. Mexico D.F.: Editorial

[1946]. Society and Nature: a Sociological Inquiry. New Jersey: The Lawbook Exchange, 2000.

[1948]. Law, State and Justice in the Pure Theory of Law. In.: [1957]. What is Justice? - Justice, Law and Politics in the Mirror of Science. New Jersey: The Lawbook Exchange, 2000.

[1953]. ¿Que és la Teoría Pura del Derecho? Trad. Ernesto Garzón Valdéz. Mexico DF: Distribuiciones Fontamara, 1991.

[1959]. Uma Teoria "Realista" y la Teoria Pura Del Derecho. In..Contribuiciones a la Teoría Pura del Derecho. México DF: Distribuciones Fontamara, 2003.

[1960]. Reine Rechtlehre - Mit einem Anhang: Das Problem der Gerechtigkeit. Zweite, völlig neu bearbeitete und erweiterte Auflage. Wien: Franz Deuticke, 1960.

[1960]. Teoria Pura do Direito. Trad. João Baptista Machado. 6a ed., São Paulo: Martins Fontes, 1999.

[1960]. Pure Theory of Law. Trad. Max Knight. Berkeley: University of California Press, 1967

[1960]. Teoria Pura del Derecho. Trad. Roberto Vernengo. Mexico D.F.: Editorial Porrua, 2005.

[1979]. Allgemeine Theorie der Normen - Im Auftrag des Hans Kelsen-Instituts aus dem Nachlaß herausgegeben von Kurt Ringhofer und Robert Walter. Wien: Manz, 1979.

[1979]. General Theory of Norms. Oxford: Clarendon Press, 1991.

[1979]. Teoria Generale delle Norme. Trad. Mirella Torre. Torino: Giulio Einaudi, 1985.

[1979]. Teoría General de las Normas. Trad. Hugo Carlos Delory Jacobs. Mexico DF: Trillas, 1994.

LOSANO, Mario [1976]. Introdução. In.: [1960]. O Problema da Justiça. Trad. João Baptista Machado. 3a ed., São Paulo: Martins Fontes, 1998.

MÉTALL, Rudolf Aladár [1976]. Hans Kelsen - Vida y Obra. Trad. Javier Esquivel. Mexico DF: Instituto de Investigaciones Jurídicas - UNAM, 1976.

PAULSON, Stanley [1998]. Introduction. In.: PAULSON, Stanley et PAULSON, Bonnie L. (Org). Normativity and Norms. Critical Perspectives on Kelsenian Themes. Oxford: Clarendon Press, 1998.

RAZ, Joseph [1981]. The Purity of the Pure Theory. In.: PAULSON, Stanley et PAULSON, Bonnie L. (Org). Normativity and Norms. Critical Perspectives on Kelsenian Themes. Oxford: Clarendon Press, 1998.

ROSS, Alf [1969]. El Concepto de Validezy Otros Ensayos. México DF: Distribuiciones Fontamara, 2001.

SGARBI, Adrian [2007]. Hans Kelsen - Ensaios Introdutórios (2001-2005). Rio de Janeiro: Lumen Iuris, 2007. 
STRUCHINER, Noel [2005]. Algumas "Proposições Fulcrais" Acerca do Direito: O Debate Jusnaturalismo vs. Positivismo. In.: MAIA, Antonio Cavalcanti et alli (Org.). Perspectivas Atuais da Filosofia do Direito, Rio de Janeiro: Lumen Iuris, 2005.

Trabalho enviado em 15 de outubro de 2017. Aceito em 26 de outubro de 2017. 